\title{
Development of a City Bike System on the Example of the City of Lublin
}

\author{
Jacek Caban $^{1}$ and Agnieszka Dudziak ${ }^{1 *}$ \\ ${ }^{1}$ University of Life Sciences in Lublin, Faculty of Production Engineering, Department of Power \\ Engineering and Transportation, Gtęboka 28, 20-612 Lublin,, Poland; Email: \\ agnieszka.dudziak@up.lublin.pl,jacek.caban@up.lublin.pl
}

\section{*Corresponding Author: Agnieszka Dudziak}

\begin{abstract}
The insertion of a city bike that complements the public transport system in large agglomerations, and mainly in the most crowded city centers, seems to be a very good solution that can contribute to reducing air pollution and reducing noise levels. In many situations, bicycle transport can perfectly fill deficiencies in public transport, e.g. at night, on holidays and on days when buses run to a limited extent. The article presents the functioning of the city bike system in Lublin since 2014. The first part of this article presents basic data on the city bike system in Lublin together with a map of bicycle stations, followed by data on the number of rentals, rental time, number of bicycle users, etc. Selected user opinions obtained on the basis of the survey were also presented. Finally, based on the analysis, final conclusions were formulated. The city bike system is used by about $10 \%$ of the population of the city of Lublin.
\end{abstract}

Keywords: Public transport, logistics, bicycle rental, city bike system

\section{Introduction}

Meeting the transport needs of society is realized using different transport systems. The choice of means of transport depends on the predisposition of a particular person and the susceptibility to transport of moved goods. City residents have at their disposal a public transport system (road or railway), passenger cars, taxis, bicycle or on foot. One of the possibilities of sustainable transport consists in non-motorized transportation cycling transport respectively inclusion of cycling in urban transport $[1,2]$.

In many European cities, there is a city bike system that complements the existing transport network, e.g. Amsterdam, Berlin, Brno, Bucharest, Copenhagen, Lublin, Warsaw or Zilina. The first generation of public bicycles was established on July 28, 1965 in Amsterdam. Cycling transport represents a mode of transport that provides efficient transport requirements especially for short as well as long distances [2]. Getting around by bike also has a good effect on human health, improves overall physical condition and good for the cardiovascular system. The continuous 
increase of human activity entails the systematic development of systems and means of transport, which causes the emergence of various new threats and the intensification of existing ones. In the urban zone, the phenomenon of transport congestion and environmental pollution through exhaust fumes from vehicles powered by internal combustion engines are particularly onerous.

Environmental impacts of means of transport are unfavorable and often have unavoidable character [3,4]. Problems of noise pollution [5-7] and emissions from transport are the subject of many scientific studies [8-13]. The transportation problems related to traffic accidents and collisions represent a constant problem undertaken by the many researchers, as evidenced by numerous publications in this field, for example [14-17]. Poliak et al. [18] present the issues concerning social law in road transport include a safety road transport. In turn, Kampf et al. [19], studied the macroeconomic evaluation of projects regarding the traffic constructions and equipment.

The fact of spatial distribution of jobs, human habitats or resources creates the need for human movement. The main purpose of transport operation is to meet this need using appropriate means. The choice of means of transport is influenced by many factors, such as the availability of a particular means, safety, travel convenience, personal preferences of travelers. The final selection is always subjectively made [20]. Changing habits is possible but requires a long time and consistent action. Creating an efficient public transport system that meets the expectations of residents is one of the key tasks for management boards of territorial units [21,22]. Currently, the main goal of such a system is to reduce congestion and the negative effects it causes [23].

As it turns out, it is becoming increasingly difficult to move around the urban agglomeration with your own car, various alternative solutions are emerging, among which the solution in the form of a city bike seems to be quite popular lately. These days, the inflow of EU funds has contributed to the development of transport infrastructure throughout Poland. New sources of financing have also forced new forms of management and innovative infrastructure solutions. One of the manifestations of this situation is represented by the construction of numerous bicycle paths, which, in addition to recreational form, have taken the form of alternative urban transport. The introduction of a city bike as a complement to the public transport system in large agglomerations, and mainly in the most crowded city centers, seems to be a very good solution.

This article presents the options of putting into the operation the city bike system in the city of Lublin. The manuscript discusses the development of the transport policy of the city of Lublin, basic information about the city bike system, its advantages and disadvantages, existing infrastructure and development perspectives. Statistical data from the period 2014-2018 regarding the operation of the city bike system and selected user opinions obtained from surveys was analyzed. 


\section{Development of the Transport Policy of the City of Lublin}

Lublin is one of the larger cities of south-eastern Poland and the capital of the Lublin Voivodeship. In 2011, in Lublin, the city authorities began to implement the principles of communication policy, which assumed a reduction of the arduousness of transport for the environment and ensuring the safety of transport for Lublin residents while minimizing the economic and social transport costs. The aim of the implemented Bicycle Policy of the city of Lublin is to support the idea of city bike as an effective and non-conflict form of transport in urban space. It was assumed that a bicycle should become an alternative means of transport in the city and should ultimately be treated as a full means of transport on a par with bus transport.

As the main strategy, assumptions have been made that the proliferation of bicycle transport will bring many benefits to the city, mainly ecological, economic and social [24,25]. This will be done by:

- achieving $100 \%$ travel destinations in a short time, especially in the city center,

- $\quad$ reducing parking problems,

- $\quad$ reducing the demand for transport space and thus clearing the streets crowded with traffic,

- improving the quality of living space in the city due to the reduction of noise levels and the amount of pollution,

- $\quad$ reducing the threat posed by vehicle traffic,

- the possibility of connecting a bicycle with other means of public transport.

The strategic goal of the development of Lublin's communication system in the long term by 2025 is to achieve at least a $15 \%$ share of cycling in the total number of trips within the city. In the medium term to 2020 , this share of $10 \%$ was assumed.

The achievement of these goals will only be possible if the area of the whole city is made available for cycling and conditions for safe cycling are created with a feeling of comfort comparable to that achieved by using other means of transport. In particular, care should be taken to develop bicycle routes creating a coherent and attractive network for cyclists. No less important is to take measures to build public support for the development of cycling, activities to promote the safe coexistence of drivers, pedestrians and cyclists, and activities to promote the bicycle as an alternative means of transport.

\subsection{Development of a City Bike System in Lublin}

The first plans to launch the public bike rental system date back to 2010, when it was intended to launch them by the Municipal Sports and Recreation Center in Lublin. Unfortunately no suitable funding source was found. In mid-2012, the idea of a city bike in Lublin returned. For the second time, the city applied for an EU subsidy for rental. They called for a tender but no winner was 
selected. The idea for the venture again came from the Municipal Sports and Recreation Center. It was planned to create 40 stations for 400 bicycles. In December 2013, Lublin announced another, on the same conditions, tender for the creation of a municipal bicycle rental.

Two companies entered the tender: Nextbike from Wroclaw and BikeU from Warsaw, which undertook to create and manage a bicycle rental system by 2019. The only criterion was the price, which is why the Municipal Office of Lublin chose Nexbike with a contract worth PLN 5.2 million. Thus, the Lublin City Bike joined the Nextbike systems existing in Wroclaw, Warsaw, Opole, Poznan and Sopot.

The city bike system works from April to the end of October. The stations are monitored and the bicycles are equipped with GPS transmitters, informing the control panel about its location. Initially, the city's inhabitants received 400 bicycles at 40 automatic rental stations. Riding for the first 20 minutes is free, an hour is charged 1 PLN, for the second hour - 3 PLN, and for the third and each subsequent - 4 PLN.

\section{Data and Methods}

Source data for the analysis of the development of city bike transport come from the website of the administrator of this system in Lublin and the next bike company. Statistical data has been analyzed since the inception of the city bike system in the city of Lublin. The analysis of the state of development of the city bike system covers the period from 2014 to 2018. The analysis is supplemented by graphic material showing the development of the city bike system in Lublin.

Table 1 Socio-demographic profile of respondents participating in the survey. Source: authors

\begin{tabular}{lcc}
\hline \multicolumn{1}{c}{ Profile of respondents } & $\begin{array}{c}\text { Number of } \\
\text { respondents }\end{array}$ & Share of respondents \\
\hline Total: & 140 & 100.0 \\
\hline 1. Gender & 42 & 30.0 \\
a) woman & 98 & 70.0 \\
b) man & - & - \\
\hline 2. Age & 108 & 77.1 \\
a) up to 18 years & 15 & 10.7 \\
b) 19-25 years & 16 & 11.4 \\
c) 26-40 years & 1 & 0.7 \\
d) 41-60 years & & \\
e) ower 60 years & 57 & 40.7 \\
\hline 3. Place of residence & 26 & 18.6 \\
a) village & 14 & 10.0 \\
b) city up to 100,000 residents & 43 & 30.7 \\
c) city 100,000 - 300,000 residents & & \\
d) city above 300,000 residents &
\end{tabular}


In addition, a survey was conducted on the preferences of Lublin residents regarding the choice of communication method, taking into account its various forms. The study was based on the author's own questionnaire. The research method used allowed to easily obtain the appropriate data set and to analyze it. The respondents represented different age groups and place of residence (both in urban and rural areas). 140 people took part in the survey. Collected answers to the questions contained in the form formed the basis for the development of research results and their analysis. The structure of the research group is shown in Table 1.

\section{Results and Discussion}

From the moment the system was launched until the end of the season in 2014 (73 days), 125,773 Lublin residents used city bikes. The average route was 1.53 kilometers, and the journey time was 18 minutes and 42 seconds. This means that cyclists in most cases did not pay for the ride. They tried to fit in the first free 20 minutes of using a city bike. The daily average loan was 1762 times. The record was recorded on October 9, 2014 - 3,647 loans. For the entire period of operation of the Lublin City Bike, two-wheelers were collected on average every 47 seconds. In the October peak every 39 seconds. Most often, bikes were rented from the station at the intersection of Krakowskie Przedmieście and Krótka Str. (7.25\%). The most popular travel routes led from Krakowskie Przedmieście Str. (the corner with Bułka Str.) to Racławickie Av. (roundabout Honorary Blood Donors), with Czwartaków Str. (Student House Helios) on Krakowskie Przedmieście Str. and from Zana Str. (ZUS) on Nadbystrzycka Str. (Lublin University of Technology). These data clearly prove the phenomenon of the bicycle as a means of transport in Lublin. People go around the city today not only for recreation. The bicycle has become a full means of transport. The winter break in the rental activity is four months. The cycling season starts from April 1 each year, but at the request of the social organization "cycling agreement" starts from March in favorable weather conditions.

As already mentioned, the municipal bicycle rental has been operating for 5 years. In the Figure 1 presents data on the number of stations and the number of city bikes available to users in subsequent years of station operation. It can be clearly seen that the trend is growing and the concept is constantly evolving and increasing both the cycling infrastructure and the number of city bike stations. In 2016, the city bike system was developed and expanded to include more bicycle stations and the number of bikes increased more than doubled (see Fig. 1). 


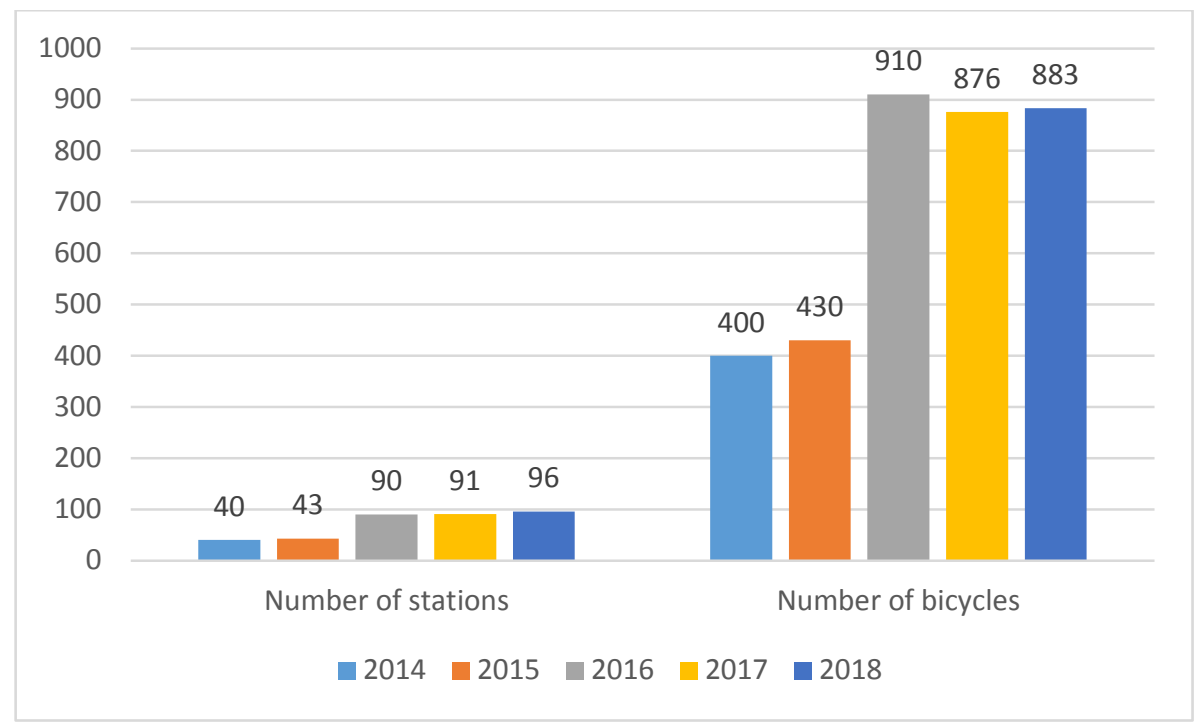

Fig. 1 Number of stations and bikes available in the system at the turn of 2014-2018. Source: authors

The number of active users of the city bike system and the number of successful rentals in a given period of time are presented in Figure 2.

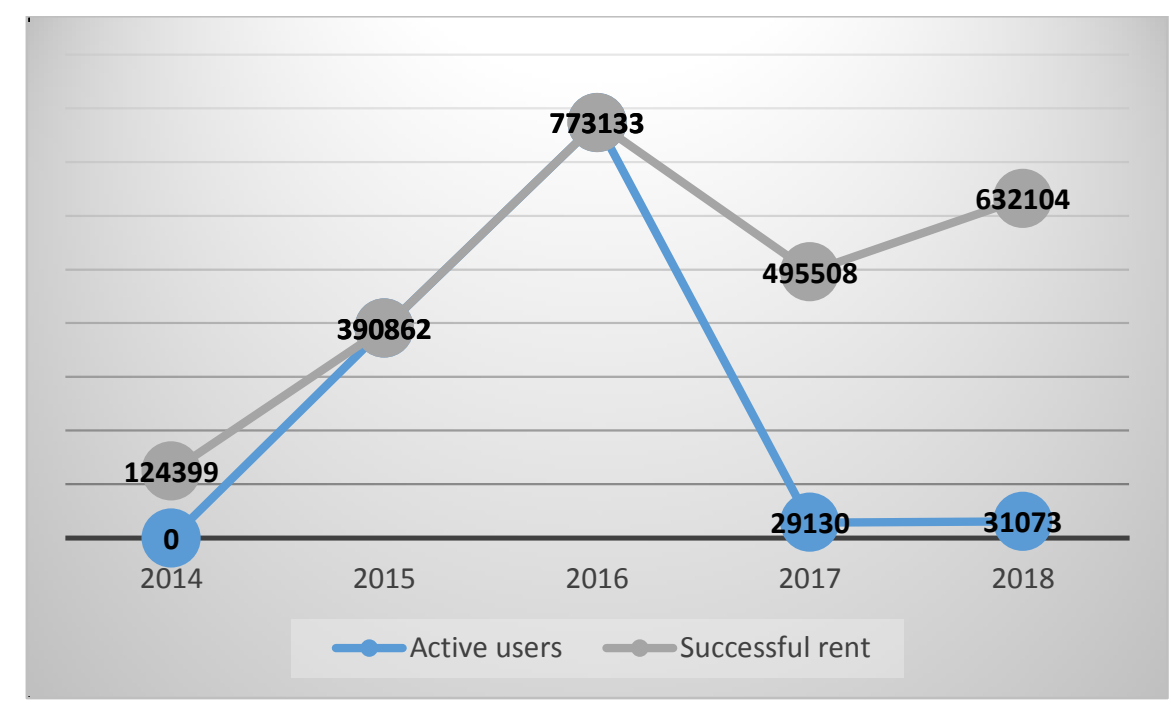

Fig. 2 Value of active users of city bike and successful rents, Source: authors

Based on the analysis of the data, it can be seen that the record of bike rentals fell in 2016 (773,133 time). Source data also indicates that this was the period of the largest number of registered users, however, according to the authors, this result may be falsified, as subsequent years show a much smaller number of active users. It seems that in 2014 and 2016 the number of bicycle rentals was recognized as the number of active users. For example, in 2017, 29,130 active users rented 495,508 bikes from the system. As can be seen in the chart, after 3 years of increase in the number of loans in the following year (2017), the number of loans decreased, and in 2018 the value increased again. It can therefore be said that the city bike system in Lublin occupies a certain position in complementing the offer of public transport for residents. Active system users constitute about $10 \%$ of the city's population. 
The Figure 3 presents the graph showing the system users' expenditures on bicycle rentals expressed in PLN. In 2014, the system was free and operated only for three months.

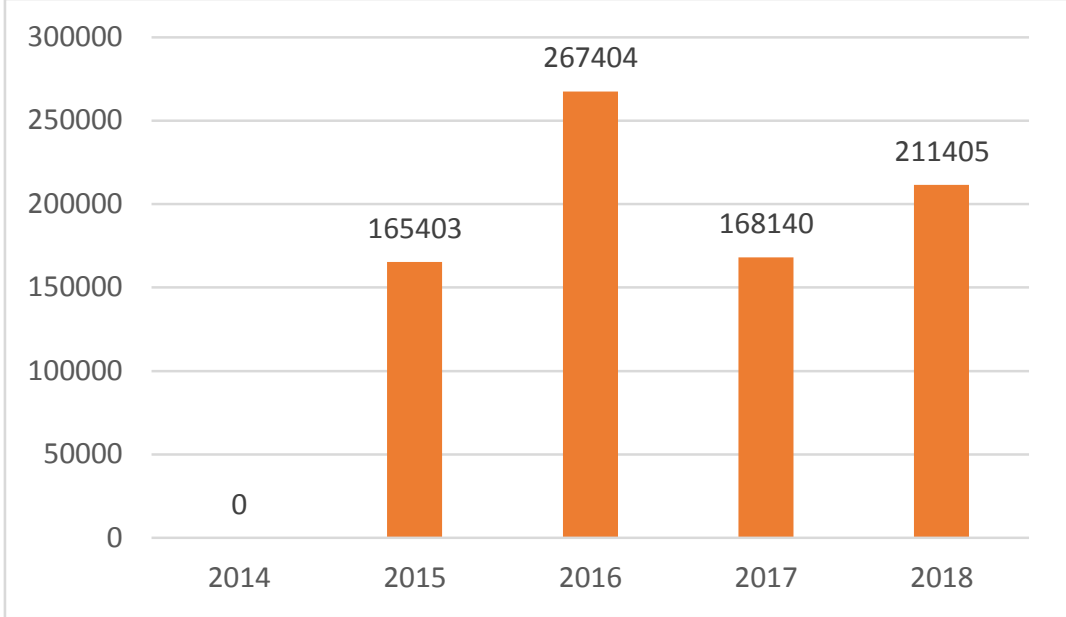

Fig. 3 Expenses incurred by city bike users at the turn of 2014-2018. Source: authors

In the following Fig. 4, the number of city bike users rented in a specified period of time at the turn of 2014-2018 expressed as a percentage is depicted.

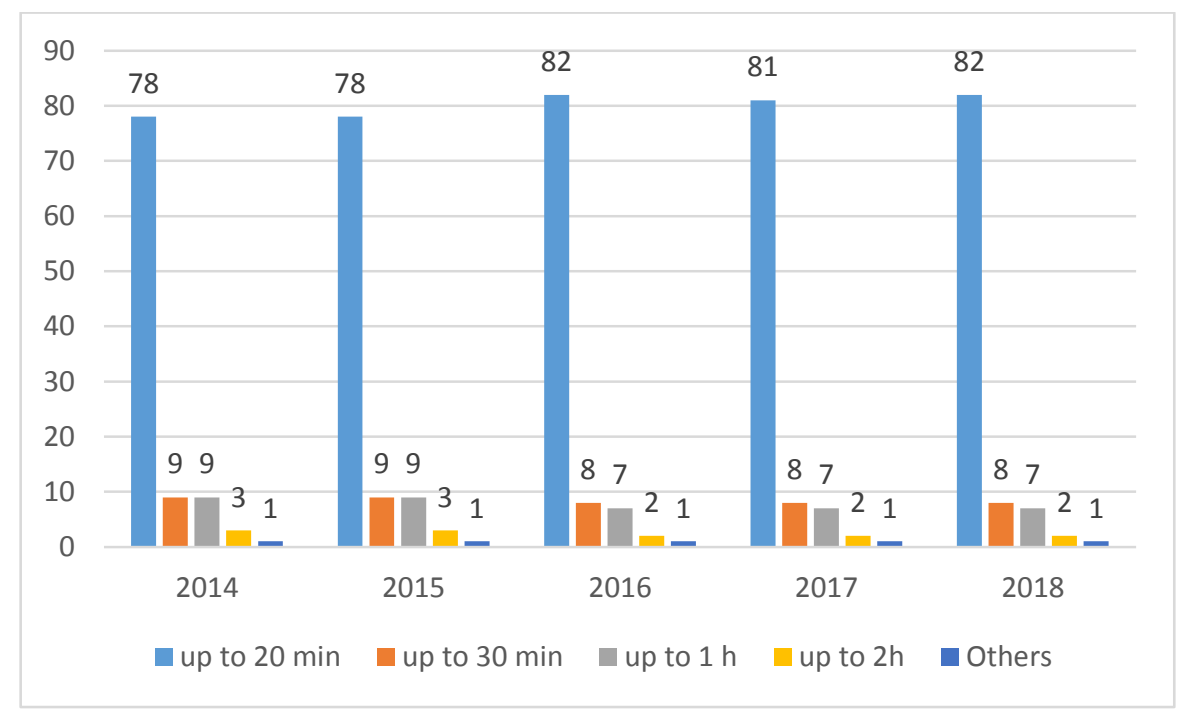

Fig. 4 The number of city bike users rented in a specified period of time (2014-2018). Source: authors

Based on the data analysis, it can be concluded that users rent bikes for the shortest possible time, i.e. up to 20 minutes. This time interval is the most financially advantageous for the user because he does not bear the costs in this period of time. The next time interval is 30 minutes and up to 1 hour. Other time intervals are marginal ( 1 to $2 \%$ of all bike rentals) (see Fig. 4).

In the case of the survey, about $70 \%$ of the research groups were represented by people living in rural areas or cities below 300,000. This translated directly into the length of the route and the average travel time. The values of these parameters are given in Table 2. The obtained results suggest access to the workplace or study located outside the place of residence. 
Table 2 Average route length and average travel time of the respondents. Source: authors

\begin{tabular}{cc}
\hline \multicolumn{2}{c}{ Data on the move between home and work } \\
\hline Average route distance & $28.47 \mathrm{~km}$ \\
\hline Average travel time & $29.14 \mathrm{~min}$. \\
\hline
\end{tabular}

Among the respondents, the vast majority indicated a car as a daily way of traveling to work or study $(63.9 \%$ of respondents, bus $-22.9 \%$, another means of communication $-9.3 \%$ (Fig. 5). Other forms of communication constituted only $3.9 \%$ of all respondents' responses.

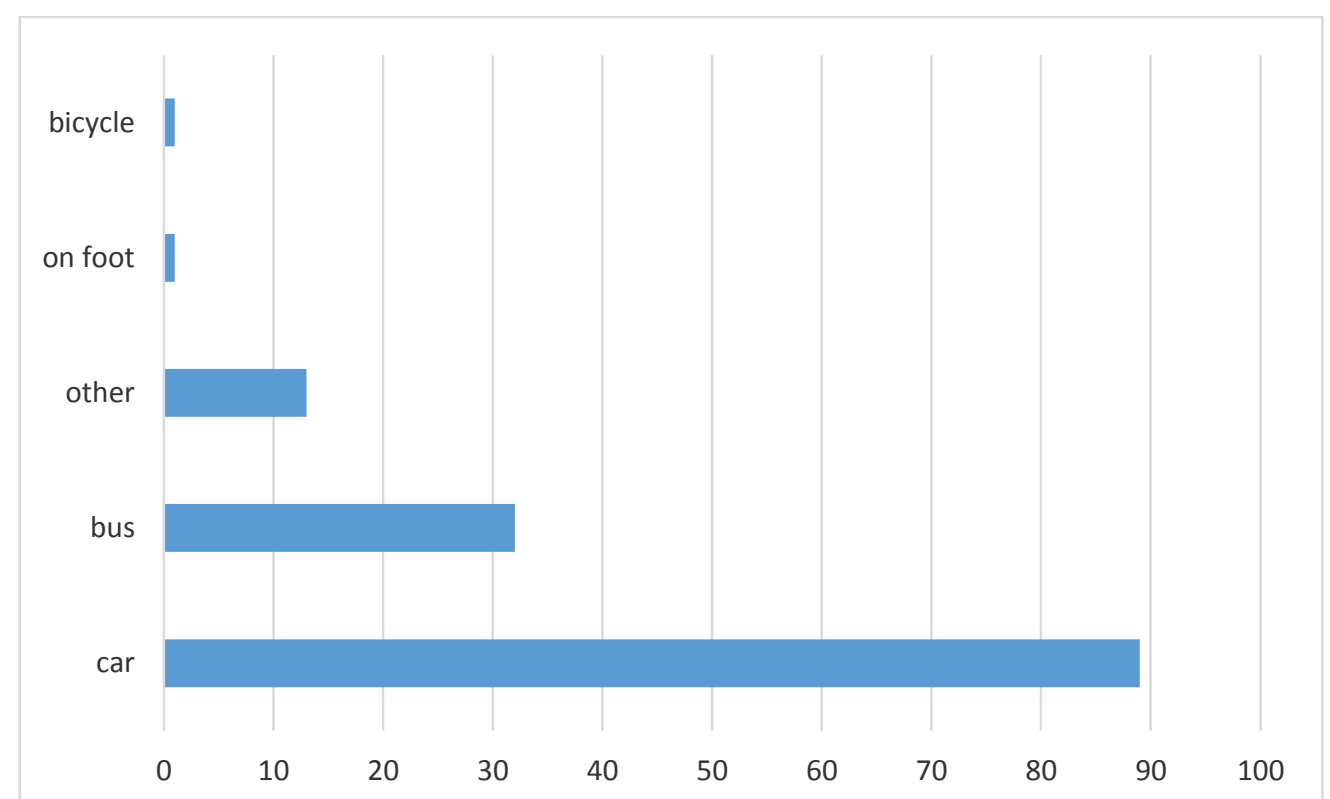

Fig. 5 Respondents' way of moving between home and workplace. Source: authors

From among the respondents choosing a car as a means of communication, the vast majority (about 96\%) consider this mode of transport as the one with the highest driving comfort and characterized by the highest travel comfort ( $93 \%$ of respondents). Many people also mentioned the issue of security (about $76 \%$ of respondents) and the fact that in their opinion this is the best choice possible (over $68 \%$ of answers). The negative perception of public transport in these aspects is noteworthy. This way of communication is definitely mentioned as the main choice among people without a driving license. It is also most often chosen because of low travel costs. In health-related issues (ecology and care for health), the ranking is topped by bicycle transport and walking. As we can observe, very similar results are obtained for both women and men. The response structure is very similar in both groups. When it comes to comfort, convenience of travel and safety, the vast majority of respondents chose a car. In the category of ecology, bicycle transport comes first (see Fig. 6).

According to respondents, the choice of bicycle as a means of transport was dictated by the issue of ecology and health reasons. However, this is a low grade in terms of comfort and convenience. The bike's very low position in the safety rating of respondents is also visible (Fig. 7).

Although city bike stations have been operating in Lublin since 2014, according to own 
research, the main means of communication in Lublin is still a passenger car. This may be due to lack of infrastructure and certain restrictions on public transport. On the other hand, the trend of city bike rental remains stable, while the issue of promotion and dissemination of this solution as a key way of moving around the city is an important aspect and will certainly strengthen over time.

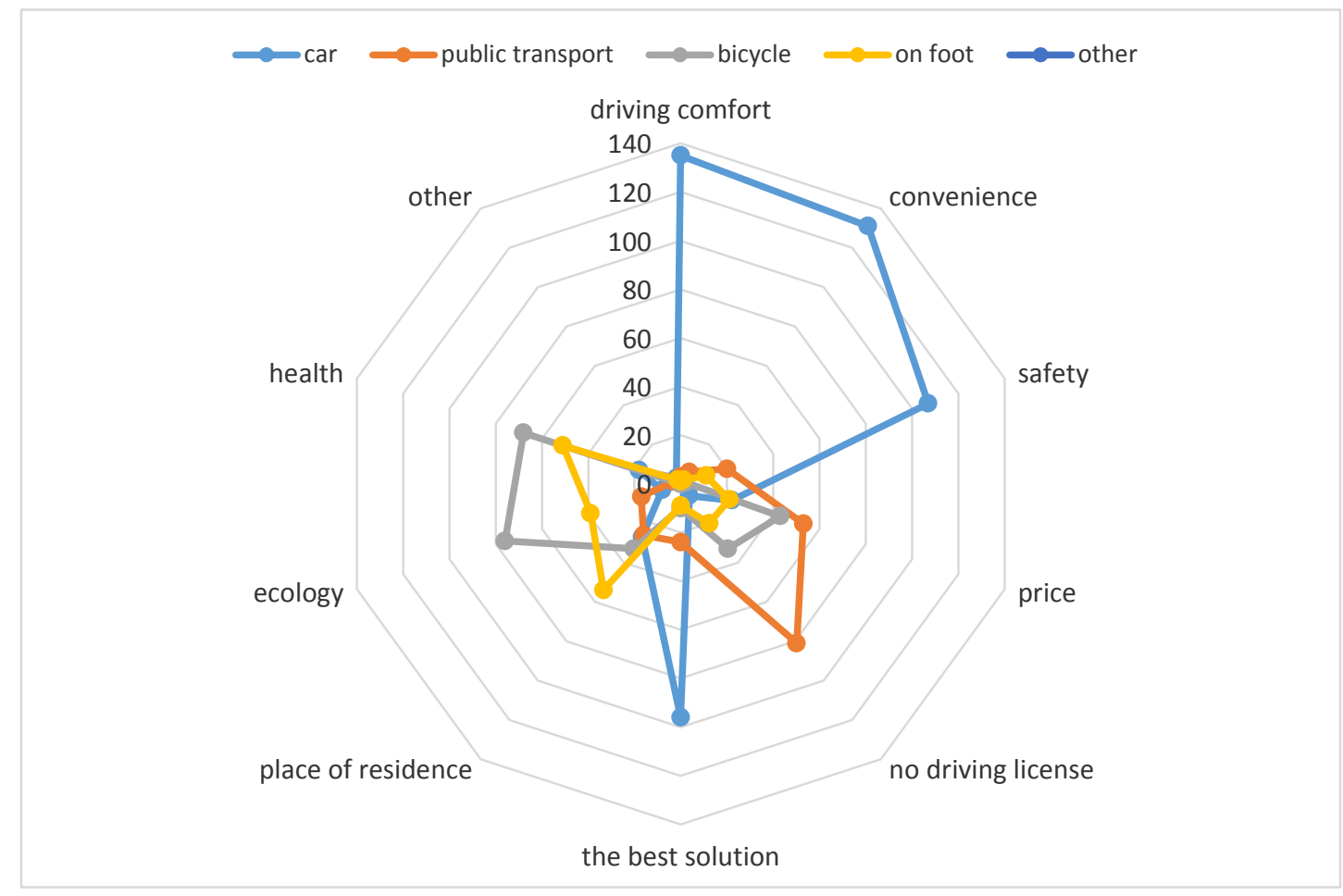

Fig. 6 Reason for choosing the means of movement in the opinion of the general respondents.

Source: authors

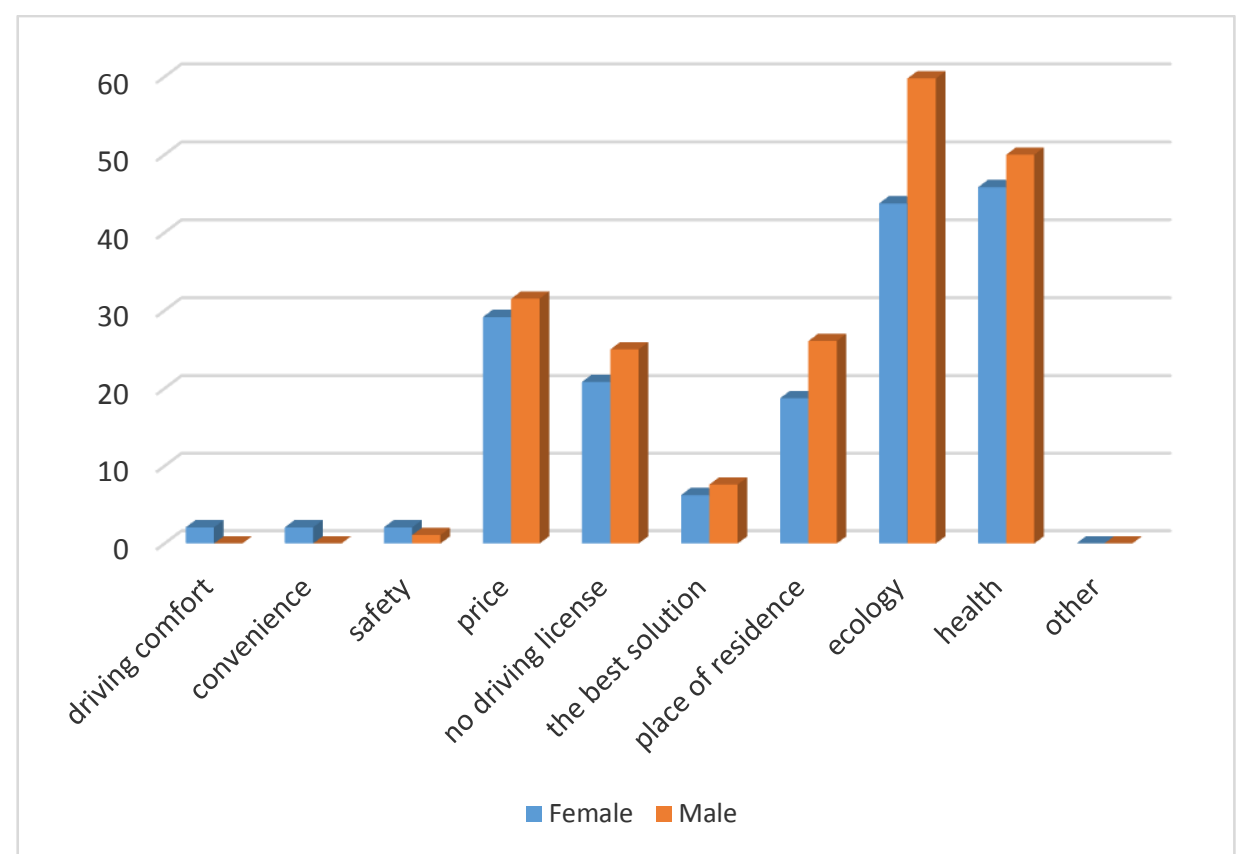

Fig. 7 Reason for choosing a bicycle as a means of movement. Source: authors 


\section{Conclusion}

Moving around the city is an increasingly complicated issue due to numerous difficulties. It is worth emphasizing that the ecological awareness of urban residents is increasing, prompting them to use alternative forms of movement. Car or urban transport is not the only company to move. One of the most popular forms is currently bicycle, shared riding with another driver or walking. In addition, new European Union regulations enforce a reduction of pressure on the environment, which is manifested in the restrictions on car traffic in city centers or renaissance of the so-called trolleybuses.

Currently, as already mentioned, one of the most desirable forms of transport in the city seems to be a bicycle that does not cause congestion, takes up little space, does not emit noise and exhaust fumes. Last year Lublin had the most modern and second largest bicycle system in Poland. During 2.5 months of system operation, over 22,000 registered people, and the number of loans exceeded 128,000 .

The urban bicycle transport system with rentals is an excellent tool for urban planners and traffic engineers involved in the strategy of designing all city communication systems. Continuous monitoring of bicycle journeys, knowledge of routes and hours selected and cycled by cyclists are basic information for the design of transport systems in large cities. By tracking this information, you can control car streams on an ongoing basis by closing or opening individual lanes on major traffic routes. These data are also necessary when developing the system of new bicycle paths.

However, at the same time, it should be emphasized that cycling will never be able to replace road transport. Nevertheless, in many situations, it turns out that bicycles perfectly complement deficiencies in public transport, e.g. at night, on holidays and on days when buses run to a limited extent.

\section{References}

[1] Rosca, E., Rusca, A., Ilie, A. \& Rusca, F. (2010). Non-motorized transportation - An educational challenge for urban communities. Theoretical and Empirical Researches in Urban Management. 8(8), 5-13.

[2] Moravčíková, K. \& Križanová, A. (2016). Corporate social responsibility focusing on the protection of the environment through the cycling transport. In Transport Means Proceedings of the International Conference, 604-608.

[3] Skrucany, T., Semanova, S., Figlus, T., Sarkan, B. \& Gnap, J. (2017). Energy intensity and GHG production of chosen propulsions used in road transport. Communications - Scientific Letters of the University of Zilina. 19(2), 3-9. 
[4] Skrucany, T., Kendra, M., Stopka, O., Milojevic, S., Figlus, T. \& Csiszár, C. (2019). Impact of the electric mobility implementation on the greenhouse gases production in central European countries. Sustainability. 11, Article number 4948. DOI: 10.3390/su11184948.

[5] Skrucany, T., Sarkan, B., Figlus, T., Synak, F. \& Vrabel, J. (2017). Measuring of noise emitted by moving vehicles. Dynamics of Civil Engineering and Transport Structures and Wind Engineering (DYN-WIND'2017); MATEC Web of Conferences. 107, UNSP 00072. DOI: $10.1051 /$ matecconf/201710700072.

[6] Sejkorova, M., Sarkan, B., Madlenak, R., Caban, J., Marczuk, A., Verner, J. \& Hyrslova, J. (2018). Effect of ferrocene addition to a gas oil on smoke opacity and engine noise. Przemysł Chemiczny. 97(8), 1312-1315. DOI: 10.15199/62.2018.8.13.

[7] Figlus, T. \& Czachor, T. (2018). Preliminary studies of the effect of travelling speed and propulsion type on the sound level in the passenger compartment of a vehicle with a hybrid propulsion system. In 11th International Science and Technical Conference Automotive Safety 2018, 1-5. DOI: 10.1109/AUTOSAFE.2018.8373346.

[8] Čampulová, M., Veselík, P. \& Michálek, J. (2017). Control chart and Six sigma based algorithms for identification of outliers in experimental data, with an application to particulate matter PM10. Atmospheric Pollution Research. 8, 700-708. DOI: 10.1016/j.apr.2017.01.004.

[9] Felkiewicz, M. \& Kubica, G. (2017). The influence of selected gaseous fuels on the combustion process in the SI engine. Transport Problems. 12(3), 135-146. DOI: 10.20858/tp.2017.12.3.13.

[10] Rimkus, A., Zaglinskis, J., Stravinskas, S., Rapalis, P., Matijosius, J. \& Bereczky, A. (2019). Research on the combustion, energy and emission parameters of various concentration blends of hydrotreated vegetable oil biofuel and diesel fuel in a compression-ignition engine. Energies. 12(15), 2978. DOI: 10.3390/en12152978.

[11] Makareviciene, V., Matijosius, J., Pukalskas, S., Vegneris, R., Kazanceva, I. \& Kazancev, K. (2013). The exploitation and environmental characteristics of diesel fuel containing rapeseed butyl esters. Transport. 28(2), 158-165. DOI: 10.3846/16484142.2013.801364.

[12] Sarkan, B., Gnap, J. \& Kiktova, M. (2019). The importance of hybrid vehicle in urban traffic in terms of environmental impact. The Archives of Automotive Engineering - Archiwum Motoryzacji. 85(3), 115-122. DOI: 10.14669/AM.VOL85.ART8.

[13] Rodzeń, A., Stoma, M. \& Kuranc, A. (2018). Examination of vehicle exhaust gas analyzers in the context of the quality of periodic vehicle technical tests. Przemysł Chemiczny. 97(5), 762766. DOI: 10.15199/62.2018.5.22. 
[14] Bačkalić, S., Jovanović, D. \& Bačkalić, T. (2014). Reliability reallocation models as a support tools in traffic safety analysis. Accident Analysis \& Prevention. 65, 47-52. DOI: 10.1016/j.aap.2013.12.004.

[15] Hudak, M. \& Madlenak, R. (2016). The research of driver's gaze at the traffic signs. In CBU International Conference Proceedings 2016, Innovations in Science and Education, 2016, 896899. DOI: $10.12955 /$ cbup.v4.870.

[16] Jurecki, R.S., Stańczyk, T.L. \& Jaśkiewicz, M.J. (2017). Driver's reaction time in a simulated, complex road incident. Transport. 32(1), 44-54. DOI: 10.3846/16484142.2014.913535.

[17] Rievaj, V., Vrábel, J., Synak, F. \& Bartuška, L. (2018). The effects of vehicle load on driving characteristics. Advances in Science and Technology Research Journal. 12(1), 142-149.

[18] Poliak, M., Mrnikova, M., Simurkova, P., Medvid, P., Poliakova, A. \& Hernandez, S. (2018). Social law in road transport like tool safety road transport. In XI International ScienceTechnical Conference AUTOMOTIVE SAFETY, Casta - Papiernicka, 18-20 April 2018, Slovakia, IEEE Proceedings Paper. DOI: 10.1109/AUTOSAFE.2018.8373317.

[19] Kampf, R., Stopka, O., Kubasakova, I. \& Zitricky, V. (2016). Macroeconomic evaluation of projects regarding the traffic constructions and equipment. In World Multidisciplinary Civil Engineering-Architecture-Urban Planning Symposium 2016, WMCAUS 2016; Procedia Engineering. 161, 1538-1544. DOI: 10.1016/j.proeng.2016.08.623.

[20] Sierpiński, G. (2011). Dilemmas of choosing an alternative means of passenger transport in the city. Logistics. 4.

[21] Szołtysek, J. (2003). Criteria determining the choice of carrier. Forwarding, Transport, Logistics. 10.

[22] Szołtysek, J. (2011). Creating mobility of city dwellers, Wolters Kluwer Polska, Warsaw.

[23] Ciesielski, M. (1986). Costs of transport congestion in cities, Publisher of the Poznań University of Economics.

[24] Bicycle Policy of the City of Lublin. Resolution No. 304-1 of the Lublin City Council of October 20, 2011.

[25] Filin, S., Filina-Dawidowicz, L. \& Chmielewski, W. (2015). Present and development perspectives of wheeled vehicles powered from the catenary. Logistics. 2. 